\title{
Self-consumption choice of residential PV owners under net-metering
}

\author{
Axel Gautier ${ }^{\mathrm{a}, \mathrm{b}, \mathrm{c}}$, Brieuc Hoet ${ }^{\mathrm{a}}$, Julien Jacqmin ${ }^{\mathrm{a}, *}$, Sarah Van Driessche ${ }^{\mathrm{d}}$ \\ ${ }^{\text {a } H E C ~ L i e ̀ g e, ~ L C I I, ~ U n i v e r s i t y ~ o f ~ L i e ̀ g e, ~ B e l g i u m ~}$ \\ ${ }^{\mathrm{b}}$ CORE, UCLouvain, Louvain-la-Neuve, Belgium \\ ${ }^{\mathrm{c}}$ CESIFO, Munich, Germany \\ ${ }^{\mathrm{d}}$ BETA, University of Lorraine, Nancy, France
}

\section{A R T I C L E I N F O}

\section{Keywords:}

Self-consumption

Self-production

Prosumer

Photovoltaic

Distributed generation

\begin{abstract}
A B S T R A C T
This paper studies the decision to synchronize household electricity consumption and production. While this behavior is beneficial for the energy system as a whole, it is not encouraged by a net-metering system. Relying on a large-scale survey conducted among households with solar PV in Wallonia, we investigate the factors impacting their decision to self-consume. As many as forty percent of our respondents declare to do so, notwithstanding the lack of incentives. The multivariate regression analysis shows that female and older residents, who tend to spend more time at home during daytime, are more likely to adapt their electricity usage by displacing their load. Prosumers with high environmental motives tend to synchronize more no matter the size of their installation. We conclude that prosumers will be further encouraged to self-consume by (1) setting monetary incentives to make consumption at the time of production more attractive, by (2) providing information to prosumers relative to their consumption/production profile and (3) by encouraging the adoption of smart devices that facilitate load shifting. These policies would lead to a higher degree of synchronization that would be beneficial for the energy system.
\end{abstract}

\section{Introduction}

More and more households install grid-connected photovoltaic panel installation on their rooftops. These decentralized production units (DPU) are grid-connected and prosumers use the grid to inject their excess power production when this exceeds their consumption and, inversely, to withdraw power when their production falls short of their consumption. DPU allow consumers to self-produce and self consume their energy. Self production refers to the local production of energy at the place of residence. Self consumption refers to the consumption of the energy produced by the DPU.

DPUs using renewable sources like solar panels play a significant role in the energy transition as they can contribute to the production of green electricity. ${ }^{1}$ For these results governments have adopted policies encouraging the deployment of decentralized production units (DPU), among which solar panels, hence, policies promoting self production. These policies include Feed-in-tariffs, Feed-in-premiums, TradableGreen-Certificates (hereinafter FiT, FiP, and TGC respectively) and investment subsidies.

However, the potential for self consumption has received a limited attention. From the many studies surveyed by Luthander et al. (2015), it appears that on average $35 \%$ of electricity is self-consumed if no specific actions and/or investments are undertaken to increase the households' self-consumption level, meaning that surplus electricity production is injected into the low-voltage network. These electricity exports are generating additional costs for the grid. First, energy grids should be reinforced to allow for power injections, and second, in case of overvoltage, the grid disconnects some PV and the electricity they produce is lost, which creates an opportunity cost. Therefore, encouraging self-consumption is an effective means to reduce grid-related costs. This can be done in two ways: via demand side management programs or via storage investments. Demand side management programs consider the opportunity to shift consumption when the DPU is producing electricity (i.e. load shifting). It can be done manually for free or via the use of timers for a limited cost. Storage devices are costlier solutions requiring investments in a battery, PV-heater or

\footnotetext{
* Corresponding author.

E-mail address: julien.jacqmin@ulg.ac.be (J. Jacqmin).

${ }^{1}$ The CO2 savings of renewable energy production depend on the carbon intensity of the generators displaced by the renewable generators. The value of solar PV

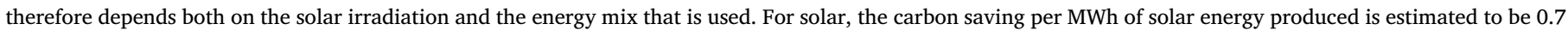

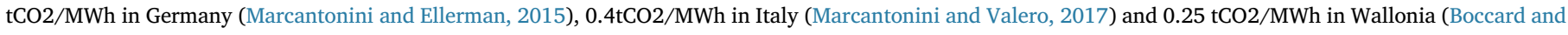
Gautier, 2015).
} 
electric vehicle.

In this context, we observe that the mechanisms used to support self-production do not necessarily encourage self-consumption. ${ }^{2}$ There are usually two mechanisms to measure and value power exchanges with the grid: net-metering and net purchasing. Under net-metering, a single meter runs backwards, meaning that imports and exports are both valued at the retail price. Under net-purchasing, two meters register imports and exports separately and value these at different prices. Gautier et al. (2018) show that with the net-metering system, prosumers have no incentive to synchronize production and consumption. ${ }^{3}$ Indeed, under this system the prosumers receive a consumption credit for the electricity they have injected into the grid and can use it whenever they want it. In other words, the grid can be considered a storage device for prosumers. By contrast, net-purchasing, by differentiating the price of energy imports and exports, encourages selfconsumption as it reduces the recorded exchanges with the grid and thereby the energy bill.

In this paper, we investigate self-producers' motives to self-consume on the basis of a survey of a representative set of prosumers from Wallonia, one of the three regions of Belgium. This specific context is interesting as the region has known a rapid deployment of domestic solar PV installations over the last decade, with over $10 \%$ of the households now being prosumers. This high diffusion rate results from a variety of support mechanisms, including a generous TGC system (Boccard and Gautier, 2015) and various investment subsidies, which have now expired. To date, the main subsidy remaining in application is the net-metering compensation mechanism. Hence, we believe that the population analyzed in our study extends beyond early adopters, who tend to have peculiar, environmental and technological preferences. The survey has also been designed so as to collect socio-economic, technological, and behavioral information about each respondent.

Despite the net-metering system in place and the total absence of financial incentives to self-consume, we observe that $40 \%$ of our respondents claim to take specific actions to synchronize further their consumption with their production, mainly via the load shifting of electric appliances. Our multivariate regression analysis allows us to disentangle the factors behind this figure. We find that women are more prone than men to self-consume, especially by adapting their usage of domestic appliances. Older, retired, prosumers also have higher stated self-consumption levels. This suggests that manual load shifting is the preferred means to increase self-consumption. We also find that prosumers declaring higher environmental preferences are more likely to self-consume. Finally, we find that neither the size nor the age of the installation affects the attitude towards self-consumption.

Our results are linked to the behavioral changes of consumers and prosumers emerging from the energy transition. Various works, reviewed by Luthander et al. (2015), have studied the technical aspects of demand side management and storage technologies in order to assess the potential to increase self-consumption. Comparing the energy consumption of prosumers and non-prosumers in the UK via interviews, Dobbyn and Thomas (2005) found that prosumers tend to be more aware of the energy intensity of various appliances and to act proactively with respect to load shifting. These behavioral changes were further confirmed by Keirstead (2007) using survey data of UK residents. However, focusing on early technology adopters can be misguiding as they tend to have strong environmental and technological preferences. By focusing on a large sample of prosumers in a region with a high diffusion rate, this paper yields a more representative picture of the situation and of its possible evolution in the near future,

\footnotetext{
${ }^{2}$ For instance, an extreme case was the French system in force until 2016, where domestic DPU were directly connected to the grid so that all the production was injected into it, without the possibility of self-consumption (Roulot and Raineri, 2018).

${ }^{3}$ We interchangeably use the terms synchronization and self-consumption.
}

hence allowing for more adequate policy recommendations.

More recently, Wittenberg and Matthies (2016) studied load shifting activities via active monitoring of PV installations by prosumers based in Germany. They found that prosumers with an interest in technology and the availability of monitoring devices positively affected the amount of actions taken to self-consume. Using smart meter data from UK prosumers, McKenna et al. (2018) show that the rate of self-consumption is heterogeneous and largely driven by the day-time electricity usage. Even under a net-metering system where prosumers face no financial incentives to self-consume whatsoever, our multivariate analysis shows that respondents are actively managing their load.

This paper, as well, examines PV owners' other behavioral changes concerning both energy savings and total energy consumption. Mixed evidence has come out as yet: while European Commission (2015) and Dobbyn and Thomas (2005), respectively focusing on France and Germany, found that the installation of a PV system led to more energy savings, Oberst et al. (2016) found no statistical difference between prosuming and non-prosuming households. The same holds concerning total energy consumption and the presence of a rebound effect. While Erge et al. (2001) found no statistical difference, Dobbyn and Thomas (2005), Bahaj and James (2007) as well as Kendel et al. (2017) found that the installation of PV panels led to a decrease in total consumption. These last sets of authors argue that energy efficiency investments are not the only channel through which energy consumption is impacted. Just as self-consumption, analyzed in this paper, awareness and informational feedback about energy usage must be considered when studying the consequences of installing PV.

\section{Methodology and data}

This paper draws on the data of a survey of PV owners in Wallonia, the southern region of Belgium. ${ }^{4}$ The sample was designed to capture a representative set of PV owners. In Nov. 2017, the web-based questionnaire was sent to a random sample of 2500 out of the 141,512 residential PV owners in the region (CWaPE, 2017). Their contact information was obtained via the CWaPE, the energy regulator, which holds the list of all PV owners in Wallonia. To be eligible for the TGC system in place, each household had to provide a contact address, which we used for this survey. In total, 585 valid responses were received with a response rate of $23.4 \%$. The questionnaire consists of 3 parts. The first collects socio-demographic information about the respondent, household-level data and information about the PV installation. The second measures the environmental and financial motivations to invest in PV (using a five-point Likert scale as possible answer). The third gathers information about the behavioral changes associated with the installation of photovoltaic panels.

Our multivariate approach aims to disentangle the various factors impacting the decision to self-consume. For this purpose, we use as a dependent variable the binary variable derived from the answer to the question "From the time you installed your photovoltaic system, have you tried to synchronize your electricity production and consumption?". A positive answer to this question means that these households have made an effort to increase their level of self consumption. However, in the survey, we do not observed the actual self-consumption level. Due to the absence of smart meters, consumers have no easy access to such information. Overall, $40 \%$ of respondents answer the question positively. An open question on the means used for increasing their self-consumption enables us to understand the behavioral changes in favor of synchronizing. For $30 \%$, self-consumption essentially goes to

\footnotetext{
${ }^{4}$ Note that due to the net-metering system in place, i.e. where the meter moves backward when electricity is sold to the grid and is stationary when users are consuming their own electricity production, revealed preference data could not be used to study the drivers of self-consumption as there are no energy smart meter in Wallonia.
} 
Table 1

Descriptive statistics.

\begin{tabular}{llrrrrr}
\hline & Variable name & Obs & Mean & Std. Dev. & Min & Max \\
\hline Dependent variables & & & & & & \\
& Self-consumption & 585 & 0.40 & 0.49 & 0 & 1 \\
& $\begin{array}{l}\text { Domestic } \\
\text { appliances }\end{array}$ & 585 & 0.30 & 0.46 & 0 & 1 \\
& Heat pump/boiler & 585 & 0.07 & 0.26 & 0 & 1 \\
Independent variable & & & & & & \\
Respondent's profile & Male & 585 & 0.88 & 0.33 & 0 & 1 \\
& Age & 585 & 54.68 & 11.48 & 27 & 88 \\
Installation & Education & 585 & 2.96 & 0.91 & 0 & 5 \\
characteristics & Size of installation & 585 & 0.19 & 0.40 & 0 & 1 \\
Residence & Age of installation & 585 & 6.56 & 2.00 & 1 & 17 \\
characteristics & Detached house & 585 & 0.70 & 0.46 & 0 & 1 \\
& Number of & 585 & 3.04 & 1.21 & 1 & 7 \\
& household & & & & & \\
members & & & & & \\
Motivations & Day-night meter & 585 & 0.53 & 0.50 & 0 & 1 \\
& Environmental & 585 & 3.20 & 0.93 & 0 & 4 \\
& motivations & & & & & \\
& Financial & 585 & 3.76 & 0.49 & 0 & 4 \\
& motivations & & & & & \\
\hline
\end{tabular}

using domestic appliances (e.g. oven, washing machines, clothes dryers, dishwashers etc.), with the second largest group of $7 \%$, citing using a heat pump and/or boiler. Therefore, using this information, we have built two separate dummies for either way of enhancing the synchronization of electricity production and consumption.

We have split our variables into 4 categories related to the sociodemographic context, PV installation, residence characteristics and motivations for the investment. Descriptive statistics are presented in Table $1 .{ }^{5}$ We first introduce 3 socio-demographic variables: male, age and education. These characteristics are proxies of two potential influences: the presence at home during daytime and energy awareness. Various studies show that women spend more time at home than men and have a higher daytime electricity use. For instance, Maron (2010) computed an index of the inequality of time spent to unpaid work in Belgium showing that women on average devote an extra $63 \%(10 \mathrm{~h} /$ week) to domestic work and parenthood. Alternatively, Torriti et al. (2015) used active home occupancy (i.e. being at home while not sleeping) as a proxy for energy demand and found that in the UK, $51.8 \%$ of women against $38.6 \%$ of men are active at home. Hence, a genderrelated explanation for higher female consumption goes hand in hand with their higher use of domestic appliances during daytime. Therefore, the effect of the variable male is expected to have a negative coefficient as manual load shifting is less feasible for them.

The sign of the coefficient of the variable age is a priori unclear. On the one hand, older people are less likely aware of the system-wide environmental benefits derived from self-consumption. On the other hand, older and retired persons are more likely to be at home when the sun shines and able to displace manually their consumption. Our PV owners are on average close to 55 years old. While the legal retirement age in Belgium is 65 , the employment rate of people older than 50 is $30 \%$, well below the $35 \%$ observed on average in Europe (Eurostat, 2018).

The variable education is a categorical variable between 0 and 5 , going from 0 (i.e. no primary education), to 5 (i.e. holding a PhD). The impact of higher education level on the choice to self-consume is unclear. If, the more educated people should be more concerned about the environmental benefits of their behavior, as discussed a.o. in Dunlap et al. (2000), they should also be more aware to understand the limited

\footnotetext{
${ }^{5}$ Note that for our two motivation-related variables we have that the sum of the mean and the standard deviation is greater than the max. This pattern is the sign of a skewed distribution. What is rather important to see here is that there is some form of heterogeneity in the preferences of the surveyed households.
}

financial incentives to adapt their consumption behavior.

Second, we control for characteristics related to the PV installation. Size of installation is a dummy variable as to whether the installation is more than sufficient to cover the household's consumption. In this case, the dummy is equal to 1 . The age of installation corresponds to the difference between the year 2017, when we made the survey, and the year of installation. Theoretically, it is unclear if and how these two variables should influence the decision to synchronize.

Third, we use three additional variables to control for housing characteristics. Type of house is a dummy variable equal to 1 when it is a fully detached house. This variable can be seen as a proxy of the wealth level of the household. Number of household members is a variable that measures the number of persons living in the housing unit. It can be seen as a good proxy of the level of electricity consumed (De Groote et al., 2016). It is unclear, however, whether it should impact the decision to synchronize. The last housing-related variable is a dummy variable that is equal to one if the house is equipped with a day-night meter. Indeed, with this kind of meter, prosumers might have a financial incentive to shift (part) of their consumption from night to daytime. ${ }^{6}$ Consequently, the effect of the day-night meter on self-consumption should be positive.

Finally, we use two measures of the motivations for the installation of PV panels. Environmental motivation is a categorical variable constructed following the answer on a Likert rating scale to the claim "You decided to install photovoltaic panels in order to protect the environment". As discussed by Wittenberg and Matthies (2016), pro-environmental motives should lead to higher self-consumption as this type of behavior is beneficial for the energy system and the environment. We use a similar proxy to control for the financial motivation for investing in PV panels. In this case, the claim was "You decided to install photovoltaic panels in order to reduce your electricity bill and thus save money". As discussed in Gautier et al. (2018), under a net-metering system, a prosumer has no financial incentive to self-consume due to the high implicit price at which the electricity produced by the PV panels is sold to the energy system.

Given the binary nature of our three dependent variables related with self-consumption, we use a probit regression. ${ }^{7}$ The standard normal density function used with this approach helps avoid two drawbacks when ordinary least square regressions are used with a binary dependent variable. First, this approach accounts for non-linearities in the effects of the determinants on our dependent variable. Second, the latter variable is always expressed as a probability between 0 and 1 . Nonetheless, due to this non-linear approach, one should be careful when interpreting the estimated coefficients of our probit regression. We only present average marginal effects (mean of the marginal effects). Hence, the effects displayed in Table 2 account for the impact of a small increase in the corresponding explanatory variable ${ }^{8}$ on one of our three dependent variables. Next to this, we include dummy variables for each of the 13 DSO present in the region in order to control for some heterogeneity related to them. One key aspect related to this spatial level is that DSO set distribution tariffs and quite heterogeneously so across the territory: they can be twice as high from one DSO to the other. Finally, we weight our observations at the DSO level to ensure a fair representative population in each DSO. The

\footnotetext{
${ }^{6}$ If the day meter runs backward to the point where it becomes negative, there is no additional payment and the excess power is supplied for free to the grid. In this case, it would be interesting to shift load from nighttime where it is costly to daytime where it is free. Alternatively, prosumers can shift to a single meter, which many chose to do. According to our survey, $47 \%$ of the prosumers have a single meter, $51 \%$ of whom switched to such a meter after the PV installation.

${ }^{7}$ Results remain unchanged if a logit regression is used instead.

${ }^{8}$ If the explanatory variable is a dummy variable one should consider a change from 0 to 1 instead of a marginal change of the variable. Similarly, if the variable is categorical, one should consider a unit increase of the variable.
} 
Table 2

Estimation results for self-consumption.

\begin{tabular}{|c|c|c|c|}
\hline Regressions variables & $\begin{array}{l}\text { (1) } \\
\text { Self-consumption }\end{array}$ & $\begin{array}{l}(2) \\
\text { Domestic } \\
\text { appliances }\end{array}$ & $\begin{array}{l}\text { (3) } \\
\text { Heat pump/boiler }\end{array}$ \\
\hline Male & $\begin{array}{l}-0.120^{* *} \\
(0.061)\end{array}$ & $\begin{array}{l}-0.174^{* * *} \\
(0.055)\end{array}$ & $\begin{array}{l}0.128 * * \\
(0.053)\end{array}$ \\
\hline Age & $\begin{array}{l}0.004^{* *} \\
(0.002)\end{array}$ & $\begin{array}{l}0.003^{*} \\
(0.002)\end{array}$ & $\begin{array}{l}-0.001 \\
(0.001)\end{array}$ \\
\hline Education & $\begin{array}{l}0.013 \\
(0.023)\end{array}$ & $\begin{array}{l}0.006 \\
(0.021)\end{array}$ & $\begin{array}{l}-0.000 \\
(0.012)\end{array}$ \\
\hline Size of installation & $\begin{array}{l}-0.016 \\
(0.051)\end{array}$ & $\begin{array}{l}-0.010 \\
(0.048)\end{array}$ & $\begin{array}{l}-0.032 \\
(0.030)\end{array}$ \\
\hline Age of installation & $\begin{array}{l}-0.013 \\
(0.010)\end{array}$ & $\begin{array}{l}-0.012 \\
(0.010)\end{array}$ & $\begin{array}{l}-0.012^{* *} \\
(0.005)\end{array}$ \\
\hline Detached house & $\begin{array}{l}0.006 \\
(0.015)\end{array}$ & $\begin{array}{l}0.012 \\
(0.014)\end{array}$ & $\begin{array}{l}-0.004 \\
(0.008)\end{array}$ \\
\hline $\begin{array}{l}\text { Number of household } \\
\text { members }\end{array}$ & $\begin{array}{l}-0.005 \\
(0.019)\end{array}$ & $\begin{array}{l}-0.015 \\
(0.018)\end{array}$ & $\begin{array}{l}-0.008 \\
(0.009)\end{array}$ \\
\hline Day-night meter & $\begin{array}{l}0.055 \\
(0.041)\end{array}$ & $\begin{array}{l}0.036 \\
(0.038)\end{array}$ & $\begin{array}{l}0.025 \\
(0.022)\end{array}$ \\
\hline $\begin{array}{l}\text { Environmental } \\
\text { motivations }\end{array}$ & $\begin{array}{l}0.089 * * * \\
(0.021)\end{array}$ & $\begin{array}{l}0.078^{* * *} \\
(0.021)\end{array}$ & $\begin{array}{l}0.048^{* * *} \\
(0.012)\end{array}$ \\
\hline Financial motivations & $\begin{array}{l}0.061 \\
(0.041)\end{array}$ & $\begin{array}{l}0.037 \\
(0.037)\end{array}$ & $\begin{array}{l}0.029 \\
(0.025)\end{array}$ \\
\hline Observations & 585 & 585 & 573 \\
\hline Pseudo likelihood & $-83,074.553$ & $-75,452.665$ & $-28,633.031$ \\
\hline Pseudo R2 & 0.0720 & 0.0702 & 0.1672 \\
\hline
\end{tabular}

Note: Standard errors in parenthesis. $*<0.1 ; * *<0.05$ and $* * *<0.01$.

weights are computed as the inverse of the sampling fraction. Note that our results remain qualitatively unchanged when ignoring DSO-level dummies and the weighting procedure used in the analysis.

\section{Results and discussion}

Our main results are presented in Table 2. The three regressions focus on different dependent dummy variables related with self-consumption. The first regression looks at the factors impacting the decision to self-consume, and the other two look at the factors determining two common ways used to synchronize more: using domestic appliances or a heat pump/boiler.

Overall we find that three factors tend to significantly impact the decision of households. First, we find that synchronizing electricity production and consumption is gender-related. ${ }^{9}$ In regression (1), we find that male respondents are on average $12.1 \%$ point less likely to take actions to self-consume than their female counterparts, even after controlling for differences in (environmental and financial) motivations. In regression (2), where we look at displacing the use of domestic appliances as a way to self-consume, we see that the average effect increases from 12.1 to 17.3 , in absolute value. Hence, females are much more likely to synchronize by using domestic appliances than consuming electricity otherwise. These results confirm our initial hypothesis that, as they tend to be more at home during daytime and as they tend to take more responsibilities with respect to domestic tasks, females are more likely to adapt their energy consumption behavior related to domestic appliances in order to synchronize more. In regression (3), on the contrary, we see that men are more likely than women to synchronize by using a boiler/heat pump. A first explanation for this result lies in the fact that being at home when the sun shines no longer plays a role in this load shifting action. A second potential explanation relates to the fact that this task is perceived differently by men and women as a load shifting activity. Finally, this task might be, all else

\footnotetext{
${ }^{9}$ What our results show is that female respondents are more likely to synchronize consumption and production with domestic appliances than male respondents. This result does not exclude that the spouse of a male respondent engages in self-consumption efforts but that these are not reported by him.
}

equal, carried out more often by men.

Age is a second factor playing a significant role. All else equal, we have that older respondents tend to synchronize more. In regression (2), we see that synchronization using domestic appliances is also more likely for relatively older respondents. One explanation for this result is that, as the sun shines during the day, it is easier to synchronize by using domestic appliances for older households. Our average respondent is close to 55 years old while only $30 \%$ of people older than 50 still work in Belgium. As many respondents no longer work, they can more easily synchronize manually by adapting their usage of domestic appliances. Replacing the age variable by a dummy retired leads to similar conclusions. ${ }^{10}$ The plausibility of this interpretation is further confirmed by the fact that, in regression (3), older people do not synchronize significantly more using pre-programmable means such as a heat pump/boiler.

A third key significant factor relates to our respondents' environmental motives with respect to their initial decision to invest in PV panels. We find that those who were relatively more driven by environmental concerns when investing in PV tend to, all else equal, synchronize more. We observe that these motives also significantly impact how they synchronize, whether it is by using a heat pump/boiler or by adapting their usage of domestic appliances.

Age of installation is another significant variable in one of our regressions. In regression (3), we see that people with a newer PV installation tend to synchronize more using a boiler/heat pump. We can explain this by the fact that these technologies are quite new, especially their automatic programmation directly linked with PV installations. Hence, recent PV installations have benefited more from these new interactions in order to increase synchronization.

Finally, the fact that the other explanatory variables are not significant is also a result per se. For instance, the adequacy between the installed PV production capacity and the respondent's consumption and the age of the installation have no significant impact on self-consumption. The same is true whatever the level of education, the age of the installation, the type of house where the PV are installed, the number of individuals living in the respondent's household, the type of meter, and the financial motivations.

Next to our three regression specifications, we made various robustness checks. First, we changed the definitions of our dependent variables (age, education, size of installation, etc.). Second, we looked at different subsamples based on the respondent's gender or if the PV installation was made before/after 2014 (when the PV support system changed). Third, we used various model specifications and estimation methods. Overall, these robustness checks tend to confirm and reinforce our main empirical findings.

\section{Conclusion and policy implications}

To ensure the success of the energy transition, governments implemented policies to support green energy production. This led to a considerable deployment of DPU among households, creating potential grid instability. Although self-production was widely encouraged, very few initiatives were taken to promote self-consumption, which would appropriately put less stress on the grid.

In 2016, the European Commission, as part of the 'Winter package', proposed a directive on the promotion of the use of energy from renewable sources to encourage renewable self-consumption. Some countries have followed the lead; Germany, for instance, has introduced incentives to favor self-consumption by funding battery storage systems. In France, the law for Energy Transition and Green Growth of 2016 provides a complete legal framework for self-consumption that was never buoyed before (Roulot and Raineri, 2018).

\footnotetext{
${ }^{10}$ This dummy is equal to one if the person is older than 60 , as the average effective retirement age is 61.3 for men and 59.7 for women (OECD, 2017).
} 
Despite the lack of monetary incentives to self-consume, we find that forty percent of our respondents try to synchronize their electricity production and consumption. Self-consumption is undoubtedly a concern among prosumers. By studying the characteristics of people who self-consume and how they go about it, we also observe that women and older persons are more likely to self-consume. As we control for differences in preferences, we suggest that they have a higher daytime electricity use while they also engage more in electricity-intensive tasks. The prosumer's environmental concern is another relevant variable affecting self-consumption. The higher this is, the more people tend to self-consume. Concerning the way people self-consume, the outcomes indicate that load-shifting using appliances that can be easily time-shifted (e.g. washing machine, dishwasher, etc.) is reported by thirty percent of the respondents. A smaller proportion of the sample declared to make use of a boiler and/or heat pump to self-consume although this trend seems to occur more among recent PV owners.

These results highlight the importance of environmental motives: even though there is no financial reason to synchronize production and consumption, a large part of our sample do try to self-consume. Hence, when setting policies to financially further encourage self-consumption, it is important not to ignore this prosocial behavior. As discussed in Braito et al. (2017) in the context of PV investments in Italy and Austria, too generous financial incentives can negatively influence non-financial motivations. Therefore, it is important to bear in mind that not only money matters: raising awareness towards environmental challenges is also a key issue. Whether it is via the education system or the dissemination of information, it is important to contribute to a better understanding of the issue.

This is particularly relevant for electricity. Indeed, since electricity is invisible, it is more difficult for individuals to observe their consumption pattern and, consequently, to modify it. Kendel et al. (2017) stressed the importance of consumer feedback to allow people to understand and to be aware of their electricity consumption. With that in mind, smart meters are being promoted internationally for the purpose of making electricity visible for consumers. This should encourage them to take actions to use electricity more efficiently for their own benefit as for the whole system. Another awareness raising policy consists in informing citizens when to adapt their consumption in order to selfconsume. And there are such initiatives, e.g. www.vaverslesoleil.be, ${ }^{11}$ offering advice, material and a simulator to boost solar autonomy. The intensity of sunshine and the time at which peak production should occur are also given everyday in the weather forecast of the main national television channels. Our survey shows that self-consumption is a concern and that initiatives increasing consumer understanding of the benefits (for the system) should be encouraged.

This does not mean that the financial incentives must be overlooked. On the contrary they should complement the awareness-raising measures. One possible way to make self-consumption more attractive from a financial point of view would be to substitute the net-metering system for the net-purchasing one. Indeed, under net-purchasing, prosumers are compensated for production exported to the grid via a feed in tariff, which makes this technology best suited to support self-consumption (see Gautier et al., 2018). In Flanders, the northernmost region of Belgium, the government plans to take advantage of the switch towards smart meters to move to the net purchasing approach.

Another possibility would be to apply a Time-Of-Use (TOU) pricing, which consists in charging prices varying with daytime periods. Let's consider two periods, a sunny one, meaning that the DPU should be producing, and a cloudy one. The price charged in period 1 would be lower than in period 2 since electricity production is mainly decentralized during the sunny period. The electricity exported to the grid would be paid at price from period 1 . In this case, prosumers would

\footnotetext{
${ }^{11}$ This is operated by a non-profit organization aiming at supporting the transition towards a greener energy system.
}

have an interest in self-consuming.

New technologies have also a key role to play. First, the emergence of smart meters will increase the awareness of consumers with respect to their energy consumption, among others by providing them accurate information related to synchronization. Second, complemented by smart devices, energy load shifting towards time where the sun shines can be greatly facilitated. Heat pumps and boilers, as analyzed in this paper, are just rudimentary existing examples. In the near future, we will likely see the appearance of connected objects controlled at distance and activated depending on the conditions of the electricity productions, i.e. when the sun shines in the right direction if we consider rooftop solar energy. It is also in the interest of policymakers to facilitate the development and adoption of such devices.

Our main conclusion is to show that PV adopters are actively engaged in self consumption and that this behavior should be encouraged further. This should be done by a combination of monetary incentives, information to consumers and adoption of smart devices. Monetary incentives require a change in the tariff structure to make consumption at the time of production more attractive. This would be achieved by a time-of-use pricing or a net-purchasing system. Information to consumers is important too. As many studies show, consumers have no clear understanding of electricity consumption and production. To promote self-consumption, prosumers should be informed of both their consumption and production profile and of the benefits of synchronizing consumption and production. Smart meters can play a key role, especially if they are complemented with smart devices that can shift the load without impeding too much the energy consumption behavior of consumers.

\section{Acknowledgements}

The authors thank the Walloon region (grant TECR) for its financial support. We also want to thank Isalyne Stassart for her technical assistance with the implementation of the survey.

\section{References}

Bahaj, A.S., James, P.A.B., 2007. Urban energy generation: the added value of photovoltaics in social housing. Renew. Sustain. Energy Rev. 11 (9), 2121-2136.

Boccard, N., Gautier, A., 2015. Le coût de l'énergie verte en Wallonie 2003-2012. Reflets et Perspectives de la Vie Economique. pp. 71-85 (LIV(1-2)).

Braito, M., Flint, C., Muhar, A., Penker, M., Vogel, S., 2017. Individual and collective socio-psychological patterns of photovoltaic investment under diverging policy regimes of Austria and Italy. Energy Policy 109, 141-153.

CWaPE, 2017. L'analyse des prix de l'électricité et du gaz naturel en Wallonie (clients résidentiels sur la période de janvier 2007 à juin 2017), CD-17g17-CWaPE-0030.

De Groote, O., Pepermans, G., Verboven, F., 2016. Heterogeneity in the adoption of photovoltaic systems in Flanders. Energy Econ. 59, 45-57.

Dobbyn, J., Thomas, G., 2005. Seeing the light: the impact of micro-generation on the way we use energy. Qualitative research findings. Hub Research Consultants, London, on behalf of the Sustainable Consumption Roundtable [online]. Available at 〈http:// www.sd-commission.org.uk/data/files/publications/Micro-generationreport.pdf〉.

Dunlap, R.E., Van Liere, K.D., Mertig, A.G., Jones, R.E., 2000. New trends in measuring environmental attitudes: measuring endorsement of the new ecological paradigm: a revised NEP scale. J. Soc. Issues 56 (3), 425-442.

Erge, T., Hoffmann, V.U., Kiefer, K., 2001. The German experience with grid-connected PV-systems. Sol. Energy 70 (6), 479-487.

European Commission, 2015. Best practices on renewable energy self-consumption. Commission staff working document. COM (2015), 339 (final).

Eurostat, 2018. Eurostat Database. European Commission, Luxembourg.

Gautier, A., Jacqmin, J., Poudou, J.-C., 2018. The prosumers and the grid. J. Regul. Econ. 53 (1), 100-126.

Keirstead, J., 2007. Behavioural responses to photovoltaic systems in the UK domestic sector. Energy Policy 35 (8), 4128-4141.

Kendel, A., Lazaric, N., Maréchal, K., 2017. What do people 'learn by looking' at direct feedback on their energy consumption? Results of a field study in Southern France. Energy Policy 108, 593-605.

Luthander, R., Widén, J., Nilsson, D., Palm, J., 2015. Photovoltaic self-consumption in buildings: a review. Appl. Energy 142, 80-94.

Marcantonini, C., Ellerman, D., 2015. Implicit carbon price of renewable energy incentives in Germany. Energy J. 36 (4), 205-239.

Marcantonini, C., Valero, V., 2017. Renewable energy and $\mathrm{CO}_{2}$ abatement in Italy. Energy Policy 106, 600-613.

Maron, L., 2010. La parentalité et l'emploi: quel défi pour les politiques publiques belges 
au regard de la situation enEurope? (Ph.D. Thesis). Université Libre de Bruxelles. McKenna, E., Pless, J., Darby, S.J., 2018. Solar photovoltaic self-consumption in the UK residential sector: new estimates from a smart grid demonstration project. Energy Policy 118, 482-491.

Oberst, C., Schmitz, H., Madlener, R., 2016. Are Prosumer Households that much different? Evidence from stated residential energy consumption in Germany. FCN Working Paper 24/2016.

OECD, 2017. Pensions at a glance 2017: OECD and G20 indicators. OECD, Paris, France. Roulot, J., Raineri, R., 2018. The impacts of photovoltaic electricity self-consumption on value transfers between private and public stakeholders in France. Energy Policy 122, 459-473.

Torriti, J., Hanna, R., Anderson, B., Yeboah, G., Druckman, A., 2015. Peak residential electricity demand and social practices: deriving flexibility and greenhouse gas intensities from time use and locational data. Indoor Built Environ. 24 (7), 891-912.

Wittenberg, I., Matthies, E., 2016. Solar policy and practice in Germany: how do residential households with solar panels use electricity? Energy Res. Soc. Sci. 21, 199-211. 